\title{
Improved Glycemic Control: A Health Literacy Initiative for the Military
}

\section{Cindy C. Cooke ${ }^{1}$, Joy P. Deupree ${ }^{2 *}$, Justin X. Moore ${ }^{3}$ and Lisle Hites ${ }^{4}$}

${ }^{1}$ School of Nursing, University of Alabama at Birmingham, 1701 University Boulevard, DNP Program, Birmingham, Alabama 35294, USA

${ }^{2}$ School of Nursing, University of Alabama at Birmingham, 1720 2nd Avenue South, NB 522, Birmingham, Al, 35294, USA

${ }^{3}$ Department of Emergency Medicine, University of Alabama School of Medicine, 619 19th Street South, OHB 251, Birmingham, AL, 35249, USA

${ }^{4}$ Department of Health Care Organization and Policy, University of Alabama School of Public Health, 330 Ryals Public Health Building, 1665

University Boulevard, Birmingham, AL 35294, USA

\section{Abstract}

Healthy People 2020 objectives seek to improve health outcomes through promotion of clear communication techniques. It is imperative for healthcare providers to understand the challenges patients face when self-managing their care, since nearly one-third of adults have difficulty understanding and utilizing healthcare information. This study examined outcomes following implementation of a health literacy initiative using an evidence-based approach for best practices. Results suggest that increased awareness of low health literacy by patients and staff may lead to better health outcomes through improved health maintenance as evidenced by a decrease in HgAlC levels, blood pressure, and cholesterol levels.

\section{Publication History:}

Received: July 09, 2015

Accepted: September 07, 2015

Published: September 09, 2015

\section{Keywords:}

Health literacy, Outcomes, Communication, Diabetes, Plain language

\section{Introduction}

For more than three decades, Healthy People initiatives have been implemented to keep the population healthy [1]. Accordingly, the health literacy objectives of Healthy People 2020 aim to improve health outcomes and reduce healthcare costs through promotion of clear communication techniques to ensure best practices [2]. However clear communication efforts have been hampered by disparate levels of health literacy and their effect on health outcomes [3].

Anecdotal clinical experiences indicate that low literate patients who read at or below a $5^{\text {th }}$ grade level can learn to self-manage diabetes through the use of symbols or pictograms, record keeping, and subsequent medication management. Patients may not be able to describe in medical terminology how they are managing their diabetes; however, in-home visits reveal that patients do understand the process. For example, home healthcare nurses report a week's worth of insulin injections may be prefilled and stored in the refrigerator in a re-sealable zipper storage bagmarked with a picture of a sun, which signals to the patient that the dose should be administered around the same time as when the sun rises [4].

The setting for this study was a United States (U.S.) Military Treatment Facility (MTF) in Alabama. Objectives included: (a) educate all staff to assess and identify patients with low health literacy; (b) provide staff training to reinforce proper communication techniques specific to content for diabetics; and (c) demonstrate a decrease in patient $\mathrm{A} 1 \mathrm{C}$ levels of diabetic patients who have historically been found to have poor glycemic control.

\section{Health Literacy}

The Institute of Medicine reports that more than 90 million Americans have difficulty reading and computing math problems and even more are estimated to have low health literacy due to the complexity of the educational literature and instructions [5]. Health literacy is defined as "the degree to which individuals have the capacity to obtain, process and understand basic health information needed to make appropriate health decisions and services needed to prevent and treat illness" [6]. The U.S. healthcare system is so complex that it challenges individuals of all literacy levels [3]. Medication selfmanagement may be extremely difficult for patients with low health literacy, particularly for those who manage chronic disease(s) $[3,5]$. Poor computational skills may lead to errors in management of disease and illness, which, in turn, may lead to return clinic visits, hospital readmissions, and escalated healthcare costs $[3,5,7]$. Limited health literacy in the United States is estimated to produce $\$ 106$ billion to $\$ 238$ billion of unnecessary costs per year to an already overburdened healthcare system [7].

In recent years, more attention has been devoted to developing simplified patient education materials written around the sixth grade reading level using plain language so that the vast majority of patients can understand the message [3,5]. The National Adult Assessment of Literacy study projected that only $12 \%$ of the American adult population is proficient in understanding health information [8]. Therefore, patient education materials should be written accordingly to increase the efficiency of health information delivery and patient understanding.

\section{The Costs of Chronic Disease}

The Centers for Disease Control and Prevention (CDC) reports that approximately half of all Americans have at least one chronic illness [9]. Chronic illnesses such as heart disease, cancer, and diabetes are the leading causes of death and disability in the U.S. chronic disease management is a challenge for patients of all literacy levels, accountings for more than $80 \%$ of healthcare spending in the U.S. [10].

While there are numerous chronic diseases that involve daily assessments, few require more attention than diabetes management [11]. Newly diagnosed cases of diabetes in the U.S. have more than tripled over the past three decades, and the CDC reports that diabetes

"Corresponding Author: Dr. Joy P. Deupree, School of Nursing, University of Alabama at Birmingham, 1720 2nd Avenue South, NB 522, Birmingham, Al 35294, USA; E-mail: deupreej@uab.edu

Citation: Cooke CC, Deupree JP, Moore JX, Hites L (2015) Improved Glycemic Control: A Health Literacy Initiative for the Military. Int J Nurs Clin Pract 2: 141. doi: http://dx.doi.org/10.15344/2394-4978/2015/141

Copyright: (c) 2015 Cooke et al. This is an open-access article distributed under the terms of the Creative Commons Attribution License, which permits unrestricted use, distribution, and reproduction in any medium, provided the original author and source are credited. 
is the most rapidly growing chronic disease in the U.S. with the highest rates among the southern states $[11,12]$. In 2006, the Council of State Governments reported that diabetes costs exceeded $\$ 132$ billion in medical expenditures, lost workdays, and permanent disability [13] The Hastings Center supports these findings and projects diabetes care will reach $\$ 192$ billion in 2020 [10]. Diabetic patients face many challenges for adequate glycemic level control including managing medications, making dietary changes, and improving exercise habits [12]. It is essential that diabetic patients with low health literacy understand the ramifications of poor blood glucose control as related to diet and exercise habits to properly manage their disease $[7,14]$.

\section{Glycemic Control Measurement}

McTigue et al. (2009) found that quarterly diabetic visits with appropriately tailored educational material can improve glycemic control and decrease adverse events [15]. The standard blood test for diabetes management and research is the glycohemoglobin test (A1C), as it provides information about a patient's blood glucose level by measuring the attachment of glucose to hemoglobin, the protein in red blood cells that carries oxygen in the form of a percentage [16] Red blood cells are continually forming and dying off, and typically live for about 120 days; therefore, the A1C test reflects the average of a person's blood glucose levels over an eight to 12 week period.The A1C does not require patient fasting therefore blood can be drawn for the test at any time of day, which is useful for primary healthcare visits usually conducted every three months [16]. The higher percentage of glucose hemoglobin, the more uncontrolled the glucose levels of the diabetic patient. The American Diabetes Association guidelines suggest that A1Clevels of 5.7-6.4 is confirmatory for prediabetes and 6.5 or higher calls for a diagnosis of diabetes [16].

\section{Diabetic Care within the United States Military}

Diabetic care expenditures in the military are parallel to those in the mainstream United States. Military healthcare costs in the Unified Medical Budget (used for military)escalated from $\$ 19$ billion in fiscal year (FY) 2001 to $\$ 52.5$ billion in FY 2012 [17]. This represented 10\% of the total base defense budget of $\$ 552$ billion excluding war efforts [17]. Considering how costly healthcare has become, improving healthcare outcomes through screening processes and wellness programs should be explored.
With healthcare costs increasing annually, more than ever it is important for healthcare providers of patients with diabetes to know the challenges associated with low health literacy as well as understand and utilize proper patient-provider communication techniques [7]. Studies indicate that providers do not always understand the health literacy ability of patients, which may lead to adverse health events due to patients' poor understanding of healthcare instructions [18]. Furthermore, there is a general lack of training among healthcare providers and staff in assessing patients' health literacy levels. Providers lack of knowledge compounds problems associated with low health literacy $[18,19]$. Adding an assessment to determine health literacy levels of patients may assist healthcare providers and staff in the development of initiatives to improve patient outcomes, especially those who face management of chronic disease(s).

\section{Study Design and Methodology}

\section{Participants}

Prior to beginning this pilot study, the military leadership and administration at the clinic as well as the Institutional Review Board at the University of Alabama at Birmingham approved materials for this study and Informed Consent was obtained from all participants.

\section{Health Literacy Initiative}

Prior to implementation of the study, the potential value of the initiative was explained to the leadership and healthcare staff of the clinic and patients. According to the administration at the facility in which this study was conducted, it is important to obtain buy-in from patients and staff at the clinic prior to implementation because clinic staff and patients often express dissatisfaction related to lengthy assessment tools and questionnaires. Patients expressed their willingness to participate and many noted their desire to improve their A1C levels.

The initiative for this study included three phases (Table 1). Phase I involved selection of diabetic patient education materials and in-service training sessions for clinic staff; Phase II encompassed implementation of a health literacy assessment and other baseline data collection (A1C, blood pressure and cholesterol) followed by enhanced diabetic patient education; and Phase III included final

\begin{tabular}{|c|c|c|c|}
\hline PHASE & ACTIONS & TOOL(S) & TIMEFRAME \\
\hline Phase I & $\begin{array}{l}\text { 1. Review and selection of diabetic education materials; } \\
\text { 2. In-service training sessions; } \\
\text { 3. Training of staff related to the NVS assessment. }\end{array}$ & $\begin{array}{l}\text { Patient education materials written } \\
\text { around a } 5^{\text {th }} \text { grade reading level } \\
\text { Demonstration of proper } \\
\text { communication techniques and teach- } \\
\text { back methods }\end{array}$ & 1 Month \\
\hline Phase II & $\begin{array}{l}\text { 1. Addition of the NVS assessment tool to determine the } \\
\text { health literacy level of each patient; } \\
\text { 2. Collection of pre-initiative blood samples and vital } \\
\text { 3igns; } \\
\text { 4. Enhanced patient education; } \\
\text { 5. Schedule follow-up return to clinic visit in } 3 \text { months }\end{array}$ & $\begin{array}{l}\text { - The Newest Vital Sign Health Literacy } \\
\text { Assessment Tool } \\
\text { - } \quad \text { Blood samples for A1C and cholesterol; } \\
\text { Blood pressure measurement } \\
\text { - } \quad \text { Teach-Back Method } \\
\text { Plain language communication }\end{array}$ & $\begin{array}{l}\text { All completed during } \\
\text { routine office visit } \\
\text { NVS approximately } 3 \\
\text { minutes to administer and } \\
\text { score } \\
\text { Follow-up reinforcement } \\
\text { as needed based on level } \\
\text { of health literacy }\end{array}$ \\
\hline Phase III & $\begin{array}{l}\text { 1. Post-initiative assessment of A1C level, blood pressure } \\
\text { and cholesterol. } \\
\text { 2. Assess for further educational needs } \\
\text { 3. Retrospective data collection and analysis }\end{array}$ & $\begin{array}{l}\text { Blood samples for A1C and cholesterol; } \\
\text { Blood pressure measurement } \\
\text { - } \quad \text { Quantitative Analysis using SPSS }\end{array}$ & $\begin{array}{l}\text { Completed during office } \\
\text { visit } 3 \text { months after initial } \\
\text { collection } \\
\text { Completed } 1 \text { month post } \\
\text { data collection }\end{array}$ \\
\hline
\end{tabular}

Table 1: Phases and timeline for initiative. 
patient assessment to collect three-month post-initiative measurements of $\mathrm{A} 1 \mathrm{C}$, blood pressure, and cholesterol levels. Upon conclusion of Phase III, data were examined for the retrospective review of findings. The entire initiative took six months to implement.

\section{Phase I}

Review of diabetic patient education materials was conducted prior to implementation of the study. Important aspects identified by the review included the use of easy-to-read words, colorful illustrations, a larger font and use of plain language. All of the current patient education materials that were being used in the clinic were reviewed in addition to other new materials that were available and on the market to purchase. Living with Diabetes: An Everyday Guide for You and Your Family was eventually chosen for use in the study. Published by The American College of Physicians Foundation, this 48-page paperbackbook is a resource that helps diabetics understand how to manage nutrition and exercise along with providing instruction for insulin self-administration[20]. Using easy-to-read words, colorful illustrations, a larger font, and plain language, the booklet can be easily understood by anyone with a $5^{\text {th }}$ grade or higher reading level. This resource has been widely distributed and well acceptedasan effort to assist patients with their diabetes management.

Staff involved in the pilot study where trained in evidenced-based best practices for patient-provider communication techniques. This included the use of plain language, materials written at the lowest grade level possible, proper techniques of the "teach back method" for patient-provider communication [3]. Staff learned to tailor patient education to meet the needs of individual patients using the patient's newly determined level of health literacy.

The Newest Vital Sign (NVS), a health literacy assessment, was chosen to measure and document each patient's level of understanding of health information. To assess health literacy using the NVS, patients were given a laminated ice cream nutrition label (14 pointfont) and asked to answer up to six questions [21]. Depending on the patient's fifth answer, an additional sixth question may be asked. The total time needed for conducting the assessment was three to five minutes. The tool evaluated both comprehension of words and numeracy or mathematical skills and is available in English or Spanish. Scoring for the NVS was calculated using a simple formula provided with the assessment: a score of $0-1$ suggests high likelihood ( $50 \%$ or more) of limited literacy; a score of 2-3 indicates the possibility of limited literacy; and a score of 4-6 usually indicates adequate literacy. Reliability of the NVS in English was established at Cronbach alpha $=0.76$. Information about the administration and interpretation of the Newest Vital Sign (NVS) health literacy assessment was provided to all staff at the clinic [21].

Unlike other traditional vital signs, the NVS is a one-time baseline assessment that provides information to the clinician regarding a patient's ability to comprehend what they hear and how well they can mathematically compute. The premise behind the NVS is that patients who can comprehend and compute accurately should have little difficulty with medication self-management. Conversely, patients who are identified with low health literacy may need additional assistance with even the simplest medication management regimens, based on the level at which they are scored by the NVS. Additionally, the result of the NVS can be kept in the patient record so that future healthcare providers are aware of the patient's capacity of understanding healthcare instructions and adjust patient instructions or education accordingly.

\section{Phase II}

Phase II of the initiative began with the addition of the NVS assessment for all diabetic patients at the clinic, conducted during routine three-month visits for diabetic care. Scores were recorded so that the provider had the information readily available. Following the NVS, other traditional vital signs were recorded (e.g., systolic and diastolic blood pressure). At the end of each patient encounter, blood samples to measure A1C and cholesterol levels were collected along with any other lab orders. Enhanced patient education followed as part of the care plan. Diabetic educational materials selected during Phase I of the study were provided to all diabetic patients by staff using enhanced provider-patient communication and the "teachback" method. Patients were allowed to ask questions to clarify any details they may not have understood completely. Following the visit, each patient was scheduled for a three-month follow-up return visit to collect post-initiative lab results in addition to blood pressure readings.

\section{Phase III}

All diabetic patients were scheduled to return to the clinic once every three months to monitor A1C levels. During the final visit, patients were assessed for A1C levels and other vital signs and cholesterol levels. Additionally, patients were provided with information regarding control of A1C levels in an effort to reinforce the information provided to them at their previous visits. The nurse practitioner assessed each patient for additional patient educational needs based on each patient's understanding of how to control A1C levels as reported by each patient. Following implementation of the initiative, aretrospective review of all data collected was conducted for analysis.

Following implementation of the initiative, a retrospective review of all data collected was conducted for analysis.

\section{Methods}

Electronic medical records were used to randomly select patients who receive healthcare from the MTF for this study. Participant inclusionary criteria were as follows: patients with a primary diagnosis of diabetes, between the ages 19 to 64, spoke English as their primary language, and reported accurate vision (some with corrected lenses). All patients invited to participate in the study provided informed consent and completed the study.

\section{Analysis/Design}

This study used a quasi-experimental retrospective study design. Variables for the analysis included baseline NVS scores for health literacy, pre- and post-initiative implementation of A1C levels, systolic blood pressure (SBP), diastolic blood pressure (DBP), and low-density lipoprotein (LDL) cholesterol levels. A signed rank test was used to compare pre-intervention and post-intervention measurements using the overall sample as well as stratified by gender and age. Assigned-rank test was used based on the small sample size; some of the stratified groups were less than 20 persons. Additionally, the distribution of some of the measures did not meet the normal distribution assumption for parametric statistical tests. P-values of less than 0.05 were considered statistically significant. 
Citation: Cooke CC, Deupree JP, Moore JX, Hites L (2015) Improved Glycemic Control: A Health Literacy Initiative for the Military. Int J Nurs Clin Pract 2: 141. doi: http://dx.doi.org/10.15344/2394-4978/2015/141

Page 4 of 5

\section{Results}

There were a total of 51 diabetic patients who completed both preintervention and post-intervention measurements for $\mathrm{A} 1 \mathrm{C}$, systolic blood pressure, diastolic blood pressure, and LDL cholesterol (Table 2). The average age for patients was 54.6 years ( 54.2 for females; 55.2 for males), with a majority of patients beingfemale (64.7\%). The average NVS score was 4.6, and more than half of the patients responded with a NVS score of 5 or higher, suggesting the probability of being health literate. As can be seen in Table 2, 20\% of the participants scored less than 4 indicating they lacked sufficient understanding of health information.

For the overall sample $(n=51)$, there was a statistically significant decrease in all measurements from pre-intervention to postintervention. The mean A1C level decreased from 7.25 preintervention to 6.82 post-intervention. Most importantly, the systolic blood pressure and LDL cholesterol decreasedby nearly $10 \%$ (Table 3 ).

For males, there was a downward trend in all measurements from pre-intervention to post-intervention; however, only changes in systolic blood pressure $(\Delta 7 \%)$ and LDL cholesterol $(\Delta 15 \%)$ reached a statistically significant level. For females, all measurements decreased significantly, with systolic blood pressure $(\Delta 10.2 \%)$ showing the largest change three months after intervention.

Among the 40-49 age group, only the systolic blood pressure significantly decreased $(\mathrm{p}=0.01)$ after the intervention. For those aged 50-59 years, all measurements showed significant decrease after intervention. Finally, for the 60 and older aged patients, both the systolic blood pressure and LDL cholesterol significantly decreased.

\begin{tabular}{|l|l|l|l|}
\hline & $\mathrm{N}$ & $\%$ & Mean (SD)* \\
\hline Total & 51 & 100 & $54.6(6.4)$ \\
\hline & & & \\
\hline Gender & & & \\
\hline Male & 18 & 35.3 & $55.2(5.6)$ \\
\hline Female & 33 & 64.7 & $54.2(6.8)$ \\
\hline Age & & & \\
\hline $40-49$ & 12 & 23.5 & $45.3(2.8)$ \\
\hline $50-59$ & 26 & 51.0 & $55.1(2.7)$ \\
\hline $60+$ & 13 & 25.5 & $62.0(1.2)$ \\
\hline NVS Score & 2 & & $4.6(1.2) \dagger$ \\
\hline 2 & 7 & 3.9 & $55.0(11.3)$ \\
\hline 3 & 14 & 13.7 & $56.1(6.3)$ \\
\hline 4 & 12 & 27.5 & $53.6(7.2)$ \\
\hline 5 & 16 & 31.4 & $55.3(4.7)$ \\
\hline 6 & 23.5 & $54.1(6.9)$ \\
\hline $\begin{array}{l}\text { Table 2: Descriptive Statistics Based on 51 Randomly Selected } \\
\text { Diabetic Patients. } \\
\\
{ }^{*} \text { Means are calculated for age (Standard Deviation). } \\
\dagger \text { Mean NVS score. }\end{array}$ & \multicolumn{2}{|l}{} \\
\hline
\end{tabular}

\section{Limitations}

Although statistically significant results are reported, there are other results that were inconclusive due tolimitations to the study such as length of study, small sample size, and narrow distribution of age and disease process. Future research is

\begin{tabular}{|c|c|c|c|c|}
\hline & $\mathrm{N}$ & $\begin{array}{l}\text { Pre- } \\
\text { Intervention } \dagger\end{array}$ & $\begin{array}{l}\text { Post- } \\
\text { Intervention } \dagger\end{array}$ & p-value ${ }^{*}$ \\
\hline OVERALL & 51 & & & \\
\hline $\mathrm{HA} 1 \mathrm{C}$ & & $7.25(1.6)$ & $6.82(1.2)$ & 0.003 \\
\hline $\begin{array}{l}\text { Systolic Blood } \\
\text { Pressure }^{\star *}\end{array}$ & & $141.68(16.7)$ & $129.76(16.8)$ & $<0.0001$ \\
\hline $\begin{array}{l}\text { Diastolic Blood } \\
\text { Pressure }\end{array}$ & & $76.90(8.7)$ & $73.08(9.3)$ & 0.003 \\
\hline LDL Cholesterol $\dagger \dagger$ & & $111.75(32.0)$ & $101.69(24.7)$ & 0.001 \\
\hline \multicolumn{5}{|l|}{ GENDER } \\
\hline Male & 18 & & & \\
\hline HA1C & & $7.83(1.9)$ & $7.4(1.7)$ & 0.1 \\
\hline $\begin{array}{l}\text { Systolic Blood } \\
\text { Pressure }\end{array}$ & & $144.00(13.1)$ & $134.11(17.8)$ & 0.002 \\
\hline $\begin{array}{l}\text { Diastolic Blood } \\
\text { Pressure }\end{array}$ & & $79.56(7.5)$ & $78.22(9.3)$ & 0.4 \\
\hline LDL Cholesterol & & $113.17(35.9)$ & $96.61(22.5)$ & 0.01 \\
\hline Female & 33 & & & \\
\hline HA1C & & $6.94(1.3)$ & $6.52(0.61)$ & 0.005 \\
\hline $\begin{array}{l}\text { Systolic Blood } \\
\text { Pressure }\end{array}$ & & $140.42(18.5)$ & $127.39(16.0)$ & $<0.0001$ \\
\hline $\begin{array}{l}\text { Diastolic Blood } \\
\text { Pressure }\end{array}$ & & $75.45(9.1)$ & $70.27(8.2)$ & 0.003 \\
\hline LDL Cholesterol & & $110.97(30.2)$ & $104.45(25.7)$ & 0.02 \\
\hline \multicolumn{5}{|l|}{ AGE } \\
\hline 40-49 Years & 12 & & & \\
\hline $\mathrm{HA} 1 \mathrm{C}$ & & $7.15(2.0)$ & $6.74(1.6)$ & 0.3 \\
\hline $\begin{array}{l}\text { Systolic Blood } \\
\text { Pressure }\end{array}$ & & $135.75(16.1)$ & $122.42(12.8)$ & 0.01 \\
\hline $\begin{array}{l}\text { Diastolic Blood } \\
\text { Pressure }\end{array}$ & & $75.33(7.6)$ & $71.92(10.2)$ & 0.3 \\
\hline LDL Cholesterol & & $130.50(47.1)$ & $124.00(27.9)$ & 0.4 \\
\hline 50-59 Years & 26 & & & \\
\hline HA1C & & $7.34(1.5)$ & $6.83(1.1)$ & 0.02 \\
\hline $\begin{array}{l}\text { Systolic Blood } \\
\text { Pressure }\end{array}$ & & $143.35(13.4)$ & $132.54(15.1)$ & 0.002 \\
\hline $\begin{array}{l}\text { Diastolic Blood } \\
\text { Pressure }\end{array}$ & & $78.35(9.2)$ & $74.85(8.6)$ & 0.04 \\
\hline LDL Cholesterol & & $105.04(25.8)$ & $95.15(22.7)$ & 0.01 \\
\hline $60+$ Years & 13 & & & \\
\hline HA1C & & $7.16(1.3)$ & $6.86(1.1)$ & 0.1 \\
\hline $\begin{array}{l}\text { Systolic Blood } \\
\text { Pressure }\end{array}$ & & $143.85(22.6)$ & $131.00(21.8)$ & 0.02 \\
\hline $\begin{array}{l}\text { Diastolic Blood } \\
\text { Pressure }\end{array}$ & & $75.46(9.0)$ & $70.62(10.0)$ & 0.07 \\
\hline LDL Cholesterol & & $107.85(19.7)$ & $94.15(9.5)$ & 0.006 \\
\hline \multicolumn{5}{|c|}{$\begin{array}{l}\text { Table 3: Means for Pre-intervention and Post-intervention Measure- } \\
\text { ments of } 51 \text { Randomly Selected Diabetic Patients. } \\
{ }^{\star} \text { Estimated from signed-rank test. } \\
{ }_{\star \star} \text { Blood pressure measured in mmHg. } \\
\dagger \text { Presented as Mean (Standard Deviation) } \\
\dagger \dagger \text { LDL Cholesterol measured in } \mathrm{mg} / \mathrm{dL} \text {. }\end{array}$} \\
\hline
\end{tabular}


Citation: Cooke CC, Deupree JP, Moore JX, Hites L (2015) Improved Glycemic Control: A Health Literacy Initiative for the Military. Int J Nurs Clin Pract 2: 141. doi: http://dx.doi.org/10.15344/2394-4978/2015/141

Page 5 of 5

recommended for broader age ranges, other disease process, and evaluation of sustained results both in civilian and military clinic environments. Additionally, there were no measurements performed to determine the knowledge of clinicians in the office who are responsible for much of the patient education.

\section{Conclusions}

Addressing patient health literacy (HL) levels and adjusting care models for optimal patient education may improve utilization of healthcare dollars. It is crucial for healthcare providers to find even small ways to decrease medical care costs. Targeted interventions are needed to evaluate health literacy levels in order to improve patient education and engage patients actively in their own healthcare.

The process of improving healthcare initiatives and outcomes through evidence-based practices is imperative. Healthcare costs have risen exponentially over the past decade and show few signs of slowing down. Addressing individual HL levels as a source of improvement for high quality patient care and healthcare outcomes can benefit quality of life as well as decrease healthcare costs. Implementation of HL educational assessment tools can enable providers to address health literacy needs at each individual patient visit. Increasing the awareness of providers to meet individual HL levels and addressing those needs will be an ongoingprocess. Continuing quality improvement to demonstrate effective techniques to improve patient comprehension of patient education is imperative as the message continues to be complicated even for those trained in the field of healthcare.

\section{Competing Interests}

The authors have no competing interests with the work presented in this manuscript.

\section{Author Contributions}

All the authors substantially contributed to the study conception and design as well as the acquisition and interpretation of the data and drafting the manuscript.

\section{Acknowledgement}

The author would like to thank the Department of Defense (DOD) and the United States Army Medical Command for allowing this study and for their focus on providing high quality healthcare to active duty service members, military retirees, and their families.

\section{References}

1. United States Department of Health and Human Services. Office of Disease Prevention and Health Promotion. Healthy People 2020 (pp.1200). Washington DC: United States.

2. Kohl HK, Berwick DM, Clancy CM, Baur C, Brach C, et al. (2014) New federal policy initiatives to boost health literacy can help the nation move beyond the cycle of costly crisis care. Health Aff (Millwood) 31: 434-443.

3. Gloria GM, Villaire M (2007) Health Literacy in Primary Care: A Clinician's Guide, ISBN-13: 978-0-8261-0229-4.

4. Hicks S (2014) Alacare Home Health and Hospice employee; personal communication.

5. Nielsen-Bohlman L, Panzer, AM, Kindig DA (2004) Institute of Medicine Committee on Health Literacy. Health literacy: A prescription to end Confusion; Washington, DC: National Academies Press.

6. Joint Committee on National Health Education Standards (1995) The national health education standards:Achieving health literacy; Washington, DC: U.S. Department of Education, Office of Educational Resources Information Center. (ERIC Document Reproduction Service No. ED386418).
7. Vernon JA, Trujillo A, Rosenbaum S, DeBuono B (2007) Low health literacy: Implications for national health policy.

8. Kutner M, Greenburg E, Baer J (2005) A first look at the literacy of America's adults in the 21 st century (NCES 2006-470), U.S. Department of Education, National Center for Education Statistics. Washington, DC: U.S. Government Printing Office.

9. U.S. Centers for Disease Control. Diabetes Public Health Resource.

10. The Hastings Center: Health care cost monitor: Projected costs of chronic diseases.

11. Willard-Grace R, DeVore D, Chen EH, Hessler D, Bodenheimer T, et al. (2013) The effectiveness of medical assistant health coaching for low-income patients with uncontrolled diabetes, hypertension, and hyperlipidemia: protocol for a randomized controlled trial and baseline characteristics of the study population. BMC Fam Pract 14: 27.

12. O'Hagan C, DeVito G, Boreham CA (2013) Exercise prescription in the treatment of type 2 diabetes mellitus. Sports Med 43: 39-49.

13. The Council of State Governments: Trends alert: Costs of chronic disease: What are states facing?

14. United States Department of Health and Human Services (2010) National action plan to improve health literacy.

15. McTigue KM, Conroy MB, Bigi L, Murphy C, McNeil M (2009) Weight Loss Through Living Well Translating an Effective Lifestyle Intervention Into Clinical Practice. Diabetes Educ 35: 199-208.

16. American Diabetes Association (2014) Diabetes Care 37, Supplement 1, Standards of Medical Care in Diabetes.

17. United States (2012) Department of Defense, United States Department of Defense Fiscal Year 2012 Budget Request, 3-2 to 3-4.

18. Jukkala A, Deupree JP, Graham S (2009) Knowledge of limited health literacy at an academic health center. J Contin Educ Nurs 40: 298-302.

19. Scheckel M, Emery N, Nosek C (2010) Addressing health literacy: The experiences of undergraduate nursing students. J Clin Nurs 19: 794-802.

20. Davis T, DeWalt D, Seligman H, Schillinger D, Arnold C, et al. (2006) Living with Diabetes: An everyday guide for you and your family, The American College of Physicians Foundation.

21. Weiss B (2011) The newest vital sign, a health literacy assessment tool. 